\title{
The social cost of rheumatoid arthritis in Italy: the results of an estimation exercise
}

\author{
G. Turchetti ${ }^{1}$, S. Bellelli ${ }^{1}$, M. Mosca ${ }^{2}$ \\ 'Institute of Management, Scuola Superiore Sant'Anna, Pisa; \\ ${ }^{2}$ Department of Clinical and Experimental Medicine, University of Pisa, Pisa, Italy
}

\begin{abstract}
SUMMARY
The objective of this study is to estimate the mean annual social cost per adult person and the total social cost of rheumatoid arthritis (RA) in Italy.

A literature review was performed by searching primary economic studies on adults in order to collect cost data of RA in Italy in the last decade. The review results were merged with data of institutional sources for estimating - following the methodological steps of the cost of illness analysis - the social cost of RA in Italy.

The mean annual social cost of RA was $€ 13,595$ per adult patient in Italy. Affecting 259,795 persons, RA determines a social cost of $€ 3.5$ billions in Italy.

Non-medical direct cost and indirect cost represent the main cost items (48\% and 31\%) of the total social cost of RA in Italy. Based on these results, it appears evident that the assessment of the economic burden of RA solely based on direct medical costs evaluation gives a limited view of the phenomenon.
\end{abstract}

Key words: Rheumatoid arthritis, Social cost, Review, Cost of illness, Italy.

\section{INTRODUCTION}

W orldwide, rheumatoid arthritis (RA) has a prevalence ranging between 0.3 and $1.6 \%$ (1-5). Literature data show that the prevalence of RA in Italy ranges between 0.31 and $0.70 \%$ (6-11). RA affects people of all ages, predominantly women; about $4 \%$ of RA patients are aged $<20$ years, $66 \%$ between $20-65$ years and $30 \%$ are above 65 years (11).

The natural history of RA is characterized by joint pain, functional limitation, and progressive joint damage, resulting in disability and reduced quality of life and survival. Literature data, in fact, show that RA causes the loss of $0.8 \%$ of disability adjusted life years and is responsible for $0.1 \%$ of all deaths in Europe as well as in Italy (12). In addition, the progressive disability characterizing the disease may affect working ability of patients leading to absenteeism and loss of employment (13-15).

In a healthcare setting where resources are limited, it is important to identify, measure and evaluate costs associated with a disease as an operational tool to support decisions on health-policy and resources allocation $(16,17)$. In rheumatic diseases, due to the introduction of new and expensive biotechnological drugs, these considerations are becoming increasingly important (18-25). The type of economic evaluation able to quantify the economic burden of RA on the society is represented by cost of illness (COI) study (26). COI studies, in fact, allow to identify the major cost components of a disease, such as direct medical and non-medical costs and indirect costs. Direct costs measure the use of resources directly related to the disease. Indirect costs are related to the loss of productivity of the patient and his/her caregivers due to the disease.

A recent systematic literature review on economic implications and pharmacoeconomic issues of RA showed how the financial impact of RA is substantial for health care systems and society worldwide (27). Annual total economic burden was estimated to be $€ 41,631$ billion in the US and $€ 45,263$ billion in Europe. Per patient annual costs were around $€ 21,000$ in the US and $€ 13,500$ in Europe. Interestingly, $\overline{\text { Corresponding author: }}$ Giuseppe Turchetti Institute of Management Scuola Superiore Sant'Anna P.zza Martiri della Libertà, 33 56127 Pisa, Italy E-mail: g.turchetti@sssup.it 
among the European countries, Italy had the highest cost for informal care and higher indirect costs (12). The review results highlighted the heterogeneity and incompleteness of literature data on the social impact of RA.

Aim of the present study was to estimate the social cost of RA in Italy with the following approach:

1) to perform a systematic literature review of economic data on the social cost of RA in Italy;

2) to perform an estimation exercise to determine the mean annual social cost per adult person and the total social cost of RA in Italy.

\section{MATERIALS AND METHODS}

\section{Systematic review of Italian literature on} the social cost of rheumatoid arthritis

A search protocol was established based on the recommendations provided by the Centre for Reviews and Dissemination (28) and the Cochrane Collaboration (29). The following inclusion criteria were applied: studies in Italian or English, adult population, published over the last decade (2002-2012). MedLine (via PubMed) was searched in November 2012 using the following Medical Subject Headings (MeSH) terms Arthritis, Rheumatoid/economics [Mesh] AND Italy. Additional studies were identified through consultation of references of relevant publications and meeting abstracts.

Data were managed in order to provide a homogeneous classification of cost categories among studies according to the economic literature (26). Costs data were inflated to Euro 2012 by the International Monetary Fund Gross Domestic Product Deflator Index for Italy (http://www.imf. org). Cost data are expressed as mean annual cost in Euro 2012.

Estimation exercise of the social cost of rheumatoid arthritis in Italy

Epidemiological and economic data resulting from the literature review were merged with data available from Italian institution- al sources as Ministry of Health, Tuscany Region, National Institute of Social Security (INPS), and the National Institute of Statistics (ISTAT).

The number of persons affected by RA in Italy was calculated by applying the literature prevalence data to the resident population in Italy (30). The gender distribution was estimated referring to the frequencies available in the literature (11).

Direct medical costs were estimated according to the following components:

- In-patient care expenditure (in-patient admissions and day hospitals for RA). Data relative to Tuscany were obtained by dividing the overall in-patient care expenditure by the number of people with RA. The Tuscany overall in-patient care expenditure was computed following three steps:

1) collecting the number of hospital discharges with principal diagnosis ICD9-CM 714.0 Rheumatoid Arthritis by type of in-patient care and diagnosis related group (DRG) from the Regional Archive of Hospital Discharge Register SKNO (http://www.ars.toscana.it/banche-dati/flussi-sanitaricorrenti/71-scheda-nosologica-skno. html);

2) collecting the Regional DRG payments (31);

3) multiplying the number of hospital discharges of point 1 to the corresponding DRG payments of point 2 . Due to the lack of updated data, we have assumed that the inpatient care cost of a patient in Tuscany was the same of a patient in Italy.

- Drugs, visits, diagnostic examinations and rehabilitation costs were taken from mean annual cost per patient data resulting from the Italian literature review.

Direct non-medical costs as transportation to and from health providers, home care fee, informal care and auxiliary devices at home, were calculated based on the percentage of the total direct costs estimated by the literature.

Indirect costs were estimated according to the following components:

- Disablement pensions and benefits paid 
by social security to patients with RA, including pensions for working total disability and benefits for partial working disability. As data about the number of disablement pensions due to RA were not available from the official source, this was estimated by multiplying the percentage of all disablement pensions for rheumatic diseases referred to RA (32) by the number of disablement pensions and benefits for rheumatic diseases provided by INPS (33). The mean annual amount of disablement pensions and benefits provided by INPS (34) was then multiplied by the number of disablement pensions and benefits for RA, resulting in the total expenditure at Italian level. From these data it was possible to estimate the mean annual expenditure per patient and then the total expenditure in Italy.

- Loss of productivity of workers with RA due to absenteeism caused by the illness. The number of workers with RA was estimated by applying the rates of employment provided by ISTAT (35) to the number of RA patients belonging to the class of working age (11) and excluding the number of totally disabled patients (calculated using public sources $(11,33$, 35). The mean number of working days lost was estimated as a weighted mean of data available in the literature $(11,13$, 36). By applying the hourly wage of an employee (37), it was estimated the mean annual lost productivity of workers with RA in Italy, per patient.

- Loss of earnings of caregivers due to patients' assistance. The number of caregivers was calculated by assuming that one out of two patients was assisted by a caregiver. The number of working caregivers was calculated by applying the proportion of people belonging to the working age class (20-65 years) on the overall population and the employment rates (35). The mean number of working days lost was assumed to be the same as estimated for patients and the hourly wage of an employee was taken from ISTAT data (37). The loss of earnings of caregivers was estimated for Italy, per patient.

\section{RESULTS}

\section{Systematic review of Italian literature} on the social cost of rheumatoid arthritis The literature search allowed identifying 6 articles, 4 studies were excluded because they did not meet the inclusion criteria. Four additional studies identified by consultation of bibliographies were considered eligible. At the end of the research 6 studies $(6,10,11,36,38,39)$ on the social cost of RA in Italy were identified. One study provided cost results by the American College of Rheumatology (ACR) RA functional classes (36). A weighted mean of cost data by ACR classes was calculated in order to have an overall mean cost. From the societal perspective the overall mean annual cost per patient ranged from $€ 6,448$ (10) to $€ 16,955$ (36) including direct medical and non-medical costs and indirect costs. By considering direct medical costs and indirect costs, the mean annual cost per patient was $€ 10,997$ (11). From the patient's perspective, RA had a cost of $€ 12,341$ per year including medical and non-medical costs and time lost from work (38). From the Healthcare System of the Lombardy Region the medical cost of a patient with RA was $€ 3,902$ (6) (Table I). The mean annual drug costs per patient with RA ranged from $€ 2,101$ (6) to $€ 2,241$ (10), including disease-modifying antirheumatic drugs and biological anti-TNF- $\alpha$ drugs. From the societal perspective, direct non-medical costs represented the main cost components of the total cost: $€ 7,501$ (44\% of $€$ $16,955)(36)$ and $€ 3,828$ (59\% of $€ 6,448)$ (10). Informal care had the greater impact on the direct non-medical costs: $€ 6,305$ ( $84 \%$ of $€ 7,501$ ) (36). RA leads to longterm incapacity of work. One patient out of three with RA reported to have modified working habits or stopped working because of the disease with a mean annual cost of $€ 6,450$ per patient (38). The mean annual number of work days lost ranged between 57 with a mean annual cost of $€$ 4,748 per patient (36) to 92 days with a cost of $€ 7,367$ (11). The impact of RA on the working life of patients worsened with increasing time since the diagnosis of the 
Table I - Mean annual social costs per patient with rheumatoid arthritis estimated by the studies included in the Italian literature review, Euro 2012.

\begin{tabular}{|c|c|c|c|c|c|c|c|c|c|c|}
\hline $\begin{array}{l}\text { Author, year of } \\
\text { publication }\end{array}$ & \multicolumn{2}{|c|}{$\begin{array}{l}\text { Leardini et al., } \\
2002^{*}(36)\end{array}$} & \multicolumn{2}{|c|}{$\begin{array}{l}\text { Osservatorio } \\
\text { Sanità e Salute, } \\
2008 \text { (11) }\end{array}$} & \multicolumn{2}{|c|}{\begin{tabular}{|l|} 
Censis- \\
ANMAR-SIR, \\
$2008(38)$ \\
\end{tabular}} & \multicolumn{2}{|c|}{$\begin{array}{l}\text { Della Rossa et } \\
\text { al., } 2009(10)\end{array}$} & \multicolumn{2}{|c|}{$\begin{array}{l}\text { Cerra et al., } \\
2009(6)\end{array}$} \\
\hline $\begin{array}{l}\text { Perspective of } \\
\text { analysis }\end{array}$ & \multicolumn{2}{|l|}{ Social } & \multicolumn{2}{|c|}{ Social } & \multicolumn{2}{|c|}{ Patient } & \multicolumn{2}{|c|}{ Social } & \multicolumn{2}{|c|}{$\begin{array}{l}\text { Healthcare } \\
\text { system }\end{array}$} \\
\hline Cost items & Euro & $\%$ & Euro & $\%$ & Euro & $\%$ & \begin{tabular}{|l|} 
Euro \\
\end{tabular} & $\%$ & Euro & $\%$ \\
\hline Direct costs & 10,726 & $63 \%$ & 3,630 & $33 \%$ & 5,891 & $48 \%$ & 6,233 & $97 \%$ & 902 & $100 \%$ \\
\hline Medical direct costs & 3,225 & $19 \%$ & 3,630 & $33 \%$ & 771 & $6 \%$ & 2,405 & $38 \%$ & 3,902 & $100 \%$ \\
\hline $\begin{array}{l}\text { Non medical direct } \\
\text { costs }\end{array}$ & 7,501 & $44 \%$ & - & - & 5,120 & $42 \%$ & 3,828 & $59 \%$ & - & - \\
\hline Indirect costs & 6,229 & $37 \%$ & 7,367 & $67 \%$ & 6,450 & $52 \%$ & $215^{\circ}$ & $3 \%$ & - & - \\
\hline Total costs & 16,955 & $100 \%$ & 10,997 & $100 \%$ & 12,341 & $100 \%$ & 6,448 & $100 \%$ & 3,902 & $100 \%$ \\
\hline
\end{tabular}

${ }^{*}$ Cost data have been calculated as weighted mean of the original cost data; ${ }^{\circ}$ it included the loss of income from work absenteeism due only to specialist (rheumatology) visits.

rheumatologist. Leardini et al. have reported that $21 \%$ of RA patients had lost their job, while $68 \%$ had to be away from work (36). Other studies show that the percentage of patients that had to change or leave their jobs increased from $18 \%$ in case of patients diagnosed in the last two years to $30 \%$ in case of patients diagnosed in the last ten years (11). Costs for RA increased significantly with worsening of the disease: direct and indirect costs were 6 times higher in the last stage (ACR IV) with respect to ACR class I (direct costs $€ 17,785$ vs $€ 2,966$, indirect costs $€ 10,613$ vs $€ 1,636$, respectively) due to the informal care cost, caregiver assistance and loss of productivity (36). The mean annual social cost of RA in Italy ranged from $€ 2.5$ to $€ 3.4$ billion, of which direct costs would contribute from $€ 1.5$ to $€ 1.7$ billion and indirect costs from $€ 1$ to $€ 1.7$ billion $(11,39)$. Cost of RA could increase up to 3.9 billion of Euro in 2029 (39).

\section{Exercise of estimate of the social cost of rheumatoid arthritis in Italy}

The prevalence of RA ranged from $0.31 \%$ (6) to $0.70 \%$ (11) in Italy and is estimated around $0.51 \%$ (10) in Tuscany. By taking the mean value, it was estimated that in Italy approximately 259,795 people aged 18 years and older are affected by RA; of these, $25 \%$ are men $(64,949)$ and $75 \%$ women $(194,846)$. The following cost components of direct costs for a patient with RA were estimated:
- In-patient care expenditure (in-patient admissions and Day Hospitals for RA). In Italy the in-patient care expenditure amounted to $€ 28,837,245$, with a mean annual cost per patient of $€ 111$;

- Drugs. A weighted mean annual expenditure for RA drugs per patient was calculated from the literature $(6,10)$ as $€ 2,107$ with an overall cost of $€ 547,388,065$ in Italy;

- Visits, diagnostic examinations, and rehabilitation. The mean annual cost per patient with RA was $€ 379$ for specialist visits, $€ 172$ for diagnostic examinations and $€ 28$ for rehabilitation (6). In Italy the corresponding total cost amounted to $€$ $98,462,305$, $€ 44,684,740$ and $€ 7,274,260$. Direct non-medical costs as transportation, home care fee, informal care and auxiliary devices at home were computed. Nonmedical direct costs represented about $70 \%$ of the total direct expenditure (36) and they amounted to $€ 6,527$ per patient. The direct non-medical costs were due to transportation costs (equivalent to $3 \%$ of total direct non-medical cost, corresponding to an overall cost of $€ 50,919,820$ in Italy), home care fee $(11 \%, € 186,532,810)$, informal care $(84 \%, € 1,424,196,190)$, and auxiliary devices at home $(2 \%, € 34,033,145)$. The following cost components of indirect costs for a patient with RA were estimated: - Disablement pensions and benefits paid by social security. In 2009, INPS provided 3,263 disablement pensions and benefits for rheumatic diseases (33). Sixteen percent 
Table II - Mean annual social costs of rheumatoid arthritis per patient and for all patients with age $\geq 18$ years in Italy, Euro 2012.

\begin{tabular}{|l|l|l|l|}
\hline & Cost per patient & $\%$ & Overall cost in Italy \\
\hline Number of people with RA & & & 259,795 \\
\hline Direct costs & 9,324 & $69 \%$ & $2,422,328,580$ \\
\hline Medical direct costs & 2,797 & $21 \%$ & $726,646,615$ \\
\hline In-patient care & 111 & $1 \%$ & $28,837,245$ \\
\hline Drugs & 2,107 & $15 \%$ & $547,388,065$ \\
\hline Specialist visits & 379 & $3 \%$ & $98,462,305$ \\
\hline Diagnostic exams & 172 & $1 \%$ & $44,684,740$ \\
\hline Non-drug therapy/rehabilitation & 28 & $0 \%$ & $7,274,260$ \\
\hline Non medical direct costs & 6,527 & $48 \%$ & $1,695,681,965$ \\
\hline Transport & 196 & $1 \%$ & $50,919,820$ \\
\hline Paid home care & 718 & $5 \%$ & $186,532,810$ \\
\hline Informal care & 5,482 & $40 \%$ & $1,424,196,190$ \\
\hline Home auxiliary devices & 131 & $1 \%$ & $34,033,145$ \\
\hline Indirect costs & 4,271 & $31 \%$ & $1,109,584,445$ \\
\hline Social security benefit of the patient & 16 & $0 \%$ & $4,156,720$ \\
\hline $\begin{array}{l}\text { Loss of productivity due to absences from work of the } \\
\text { patient }\end{array}$ & 2,831 & $21 \%$ & $735,479,645$ \\
\hline Total patient & 2,847 & $21 \%$ & $739,636,365$ \\
\hline $\begin{array}{l}\text { Loss of productivity due to absences from work of the } \\
\text { caregiver }\end{array}$ & 1,424 & $10 \%$ & $369,948,080$ \\
\hline Total costs & 13,595 & $100 \%$ & $3,531,913,025$ \\
\hline RA, rheumatoid arthris. & & \\
\hline
\end{tabular}

RA, rheumatoid arthritis.

of the disablement pensions for rheumatic diseases were provided to patients with RA (32) for a total of 522 pensions with a mean annual amount of $€ 7,941$ (34). Overall $€$ $4,156,720$ were spent for patients with RA in Italy with a cost of $€ 16$ per patient;

- The productivity lost by workers with RA due to absenteeism caused by the illness. It was estimated that 107,402 workers suffered by RA and 65 working days were lost per year. The mean annual cost for productivity lost by workers with RA was estimated $€ 735,479,645$ in Italy with a mean annual cost of $€ 2,831$ per patient.

- Loss of earnings of caregivers. It was assumed that 153,082 caregivers assisted patient with RA of which 54,004 were workers. By assuming that working caregivers lost 65 days per year, it was estimated that in Italy the loss of productivity was $€$ $369,948,080$. The mean annual cost per patient was $€ 1,424$ (Table II).

According to our exercise, in Italy the mean annual social cost per patient with RA was estimated as $€ 13,595$. The mean annual direct medical cost per patient with RA ( $€$
2,797 ) would be almost $52 \%$ higher than the Italian per capita public health spending (€ 1,842) in 2011 (40). Total direct medical costs of RA represented almost $0.6 \%$ of the Italian public health expenditure (estimated at 112 billion of Euro) in 2011 (40). Direct non-medical costs represented the largest cost component ( $€ 6,527$, $48 \%$ of the total) followed by indirect costs ( $€ 4,271,31 \%$ of the total). Overall, in Italy the mean annual cost for patients with RA would be equal to $€ 3,531,913,025$ and it represented almost the $0.23 \%$ of the Italian gross domestic product (41) (Table II).

\section{DISCUSSION}

RA is a complex and chronic disabling disease, with a female prevalence and a relevant social and economic burden on patients, families and productive system. An increase of costs is expected due to the aging of the population. The review of the Italian literature has identified a small number of studies of cost estimates of RA 
characterized by different levels of completeness. Given the lack of data that quantifies the burden of all cost items defining the social cost of RA in Italy, the present study was conducted to estimate the total impact of RA on society. Interesting observations can be made on the distribution of cost items. Direct medical costs account for the $21 \%$ of the total costs ( $€ 2,797$ out of $€ 13,595$ per patient), while the remaining $79 \%$ are non-medical costs, such as direct non-medical costs $(€ 6,527)$ and indirect costs ( $€ 4,271)$. Non-medical and indirect costs are mainly sustained by household for informal care ( $€ 5,482,40 \%$ of the total cost), by the productivity system and by the social security system ( $€ 4,271,31 \%$ of the total cost).

Based on these results, it appears evident that the assessment of the economic burden of RA solely based on direct medical costs evaluation gives a limited view of the phenomenon. As RA is a complex disease necessitating an interdisciplinary care, the assessment of disease costs should be based on a broader view including all the different aspects of patient care, including prevention, general practitioners, specialists, rehabilitation and social welfare support.

The limitation of the study resides in the fact that data are obtained with a theoretical exercise and not directly from real observation. Future studies aimed at collecting real data are needed. Nonetheless, this study represents the first attempt to quantify and discuss the real entity of the social costs associated to RA in Italy.

\section{REFERENCES}

1. Kvien TK. Epidemiology and burden of illness of rheumatoid arthritis. Pharmacoeconomics 2004; 22: 1-12S.

2. Stojakovich R, Vlajinac H, Palicobradovich D, Janosevic S, Adanja B. Prevalence of rheumatoid arthritis in Belgrade, Yugoslavia. Br J Rheumatol. 1998; 37: 729-32.

3. Guillemin F, Saraux A, Guggenbuhl P, Roux $\mathrm{CH}$, Fardellone P, Le Bihan E, et al. Prevalence of rheumatoid arthritis in France: 2001. Ann Rheum Dis. 2005; 64: 1427-30.

4. Symmons D, Turner G, Webb R, Asten P, Barrett $\mathrm{E}$, Lunt $\mathrm{M}$, et al. The prevalence of rheu- matoid arthritis in the United Kingdom: new estimates for a new century. Rheumatology 2002; 41: 793-800.

5. Abdel-Nasser AM, Rasker JJ, Valkenburg HA. Epidemiological and clinical aspects relating to the variability of rheumatoid arthritis. Semin Arthritis Rheum. 1997; 27: 123-40.

6. Cerra C, Ravasio R, Polcaro F. Il costo dell'Artrite Reumatoide: l'esperienza dell'ASL della Provincia di Pavia. Giorn It Health Technol Assess. 2009; 2: 111-7.

7. Cimmino MA, Parisi M, Moggiana G, Mela G, Accardo S. Prevalence of rheumatoid arthritis in Italy: the Chiavari study. Ann Rheum Dis. 1998; 57: 315-8.

8. Marotto D, Nieddu ME, Cossu A, Carcassi A. Prevalence of rheumatoid arthritis in North Sardinia: the Tempio Pausania's study. Reumatismo 2005; 57: 273-6.

9. Salaffi F, De Angelis R, Grassi W. Prevalence of musculoskeletal conditions in an Italian population sample: results of a regional community-based study. I. The MAPPING study. Clin Exp Rheumatol. 2005; 23: 819-28.

10. Della Rossa A, Neri R, Talarico R, Doveri M, Consensi A, Salvadori S et al. Diagnosis and referral of rheumatoid arthritis by primary care physician: results of a pilot study on the city of Pisa, Italy. Clin Rheumatol. 2010; 29: 71-81.

11. Osservatorio Sanità e Salute. Progetto di ricerca: costo sociale malattie reumatiche. Convegno "Malattie Reumatiche: disabilità, impatto sul lavoro e costi". Roma: Osservatorio Sanità e Salute 2008 Dec 4.

12. Lundkvist J, Kastang F, Kobelt G. The burden of rheumatoid arthritis and access to treatment: health burden and costs. Eur J Health Econ. 2008; 8: 49-60S.

13. Burton W, Morrison A, Maclean R, Ruderman E. Systematic review of studies of productivity loss due to rheumatoid arthritis. Occup Med (Lond) 2006; 56: 18-27.

14. Young A, Dixey J, Kulinskaya E, Cox N, Davies $\mathrm{P}$, Devlin $\mathrm{J}$, et al. Which patients stop working because of rheumatoid arthritis? Results of five years' follow up in 732 patients from the Early RA Study (ERAS). Ann Rheum Dis. 2002; 61: 335-40.

15. Quadrello T, Bevan S, McGee R. Fit For Work? Musculoskeletal disorders and the Italian labour market; 2009. Available from: http://www.fitforworkeurope.eu

16. Turchetti G, Spadoni E, Geisler EE. Health technology assessment. Evaluation of biomedical innovative technologies. IEEE Eng Med Biol Mag. 2010; 29: 70-6.

17. Turchetti G, Scalone L, Della Casa Alberighi O, Mosca M, Montella S, Cortesi P, et al. The rationale of pharmacoeconomic analysis in rheumatologic indications. Clin Exp Rheumatol. 2012; 30: 64-71S. 
18. Cortesi PA, Scalone L, D’Angiolella L, Belisari A, Fusco F, Olivieri I, et al. Systematic literature review on economic implications and pharmacoeconomic issues of psoriatic arthritis. Clin Exp Rheumatol. 2012; 30: 126$31 \mathrm{~S}$.

19. Trieste L, Palla I, Baldini C, Talarico R, D'Angiolella L, Mosca M, et al. Systemic vasculitis: how little we know about their societal and economic burden. Clin Exp Rheumatol. 2012; 30: 154-6S.

20. Kobelt G, Woronoff AS, Richard B, Peeters P, Sany J. Disease status, costs and quality of life of patients with rheumatoid arthritis in France: the ECO-PR Study. Joint Bone Spine 2008; 75: 408-15.

21. Trieste L, Palla I, Fusco F, Tani C, Baldini C, Mosca M, et al. The economic impact of gout: a systematic literature review. Clin Exp Rheumatol. 2012; 30: 145-8S.

22. Kirchhoff T, Ruof J, Mittendorf T, Rihl M, Bernateck M, Mau W, et al. Cost of illness in rheumatoid arthritis in Germany in 1997-98 and 2002: cost drivers and cost savings. Rheumatology 2011; 50: 756-61.

23. Palla I, Trieste L, Tani C, Talarico R, Cortesi P, Mosca M, et al. A systematic literature review of the economic impact of Ankylosing Spondylitis. Clin Exp Rheumatol. 2012; 30: 136$41 \mathrm{~S}$.

24. Wolfe F, Michaud K. Out-of-pocket expenses and their burden in patients with rheumatoid arthritis. Arthritis Rheum. 2009; 61: 1563-70.

25. Turchetti G, Yazdany J, Palla I, Yelin E, Mosca M. SLE and the economic perspective: a systematic literature review and points to consider. Clin Exp Rheumatol. 2012; 30: 116-22S.

26. Drummond MF, O'Brien B, Stoddart GL, Torrance GW. Methods for the economic evaluation of health care programmes. 3rd ed. Oxford: Oxford University Press 2005.

27. Furneri G, Mantovani LG, Belisari A, Mosca M, Cristiani M, Bellelli S, et al. Systematic literature review on economic implications and pharmacoeconomic issues of rheumatoid arthritis. Clin Exp Rheumatol. 2012; 30: 70-82S.

28. Systematic Reviews: CRD's guidance for undertaking systematic reviews in health care. Centre for Reviews and Dissemination; 2009 Jan. Available from: http://www.york.ac.uk/ inst/crd/SysRev/!SSL!/WebHelp/SysRev3. htm Accessed: 2013 July 22.
29. Higgins JPT, Green S. Cochrane Handbook for Systematic Reviews of Interventions Version 5.1.0 [updated March 2011]. The Cochrane Collaboration; 2011. Available from: http://www.cochrane-handbook.org Accessed: 2013 July 22.

30. ISTAT. Bilancio demografico anno 2011. Demografia in cifre. Available from: http://demo. istat.it/ Accessed: 2012 Nov 15.

31. Regione Toscana. Bollettino Ufficiale della Regione Toscana DGR 118429 Dicembre 2008 Parte Seconda n. 2 del 14 gennaio 2009. Available from: http://www.regione.toscana. it/burt Accessed: 2012 Nov 15.

32. Ciocci A, Buratti L, Coari G, Di Franco M, Iagnocco AM, Mauceri MT, et al. Artrite reumatoide: stima della frequenza dei ricoveri e valutazione dei costi della malattia. Reumatismo 2001; 53: 215-22.

33. Commissione Permanente $\left(12^{\mathrm{a}}\right.$ Igiene e Sanità) del Senato della Repubblica Italiana. Indagine conoscitiva sulle malattie ad andamento degenerativo di particolare rilevanza sociale, con specifico riguardo al tumore alla mammella, alle malattie reumatiche croniche ed alla sindrome HIV 2011. Available from: http://www.senato.it/ Accessed: 2012 Nov 15.

34. INPS. Rapporto annuale 2009. Available from: http://www.inps.it/ Accessed: 2012 Nov 15.

35. ISTAT. Rilevazione sulle forze lavoro 2011. Available from: http://www.istat.it/it/archivio/8263 Accessed: 2012 Nov 15.

36. Leardini G, Salaffi F, Montanelli R, Gerzeli S, Canesi B. A multi-center cost-of illness study on rheumatoid arthritis in Italy. Clin Exp Rheumatol. 2002; 20: 505-15.

37. ISTAT. Lavoro e retribuzioni 2008. Available from: http://www.istat.it/ Accessed: 2012 Nov 15.

38. Censis, ANMAR, SIR. Un percorso ad ostacoli, primo rapporto sociale sull'artrite reumatoide 2008. Available from: http://www. anmar-italia.it/ Accessed: 2013 July 22.

39. Cicchetti A, Ruggeri M, Gori F. Quanto costa la reumatologia. Il Sole24Ore Sanità 2010; 36: 30.

40. ISTAT. Public expenditure on health 2013. Available from: http://noi-italia2013en.istat.it/ index.php?id=53 Accessed: 2013 July 22.

41. OECD. OECD.Stat 2013. Available from: http://stats.oecd.org/ Accessed: 2013 July 22. 